\title{
Phenotypic Clustering of Indian Donkey Population Belonging to Six Agro- Climatic Regions
}

\author{
Gupta AK ${ }^{1 *}$, Kumar S ${ }^{1}$, Pal $\mathbf{Y}^{1}$, Brahmane $\mathbf{M}^{2}$, Kumar $\mathbf{B}^{3}$, Chauhan $\mathbf{M}^{1}$, Sharma $\mathbf{P}^{1}$, Singh $\mathrm{P}^{4}$, Sheokand RN ${ }^{5}$ and Aneja DR \\ ${ }^{1}$ ICAR-National Research Centre on Equines, Sirsa Road, Hisar 125001 (Haryana), India \\ ${ }^{2}$ ICAR-National Institute of Abiotic Stress Management, Baramati, Pune, Maharashtra, India \\ ${ }^{3}$ Bihar Veterinary College, Patna, Bihar, India \\ ${ }^{4}$ Veterinary Officer, Department of Animal Husbandry, Maner, Patna, Bihar, India \\ ${ }^{5}$ Department of Mathematics, Statistics and Physics, CCSHAU, Hisar, Haryana, India
}

\begin{abstract}
Donkeys support rural livelihoods and low-income farmer's family by providing economy at minimal maintenance cost. In India, donkeys constitute about $28 \%$ of total equine population but these are non-descript local donkeys without any breed characterization. This study describes phenotypic diversity among different donkey populations available in various agro-climatic regions in India including Gujarat, Rajasthan, Maharashtra, J\&K, Haryana, Bihar and Himachal Pradesh for their phenotypic clustering as a distinct breed(s) by considering each population as a separate cluster.

Biometric indices of seven local donkey populations were recorded and compared to French Poitou donkey breed which revealed that average body length of donkeys from Spiti, Gujarat, Rajasthan, Baramati, Bihar, Haryana and Leh areas was $97.09,101.18,97.60,103.68,96.31,109 \& 95.76 \mathrm{~cm}$, respectively, while Poitou donkeys had significantly higher length $(138.79 \mathrm{~cm})$ than indigenous donkey populations. Further height at wither revealed that except leh donkey population, the rest of the donkeys prevalent throughout different agro-climatic regions met a "small standard' pattern. Donkey populations from Leh were fitted in 'Miniature' donkey pattern. All local donkeys were well adapted to their agroclimatic environment and ecology as they were totally dependent upon the grass cover and roughages available within their reach for meeting their nutritional requirement. Coat colour varied across different regions. Black and brown colours were prevalent in donkeys from cold desert regions including Leh and Spiti region. Face length of donkeys from Spiti, Gujarat and Baramati were at par with each other while donkeys from Leh had smallest face length. Cluster analysis based on biometric indices revealed that exotic Poitou donkeys is an out-group as it formed a distinct cluster while Indigenous donkeys belonging to various agro-climatic zones were grouped in three clusters namely, C1-miniature or near miniature donkeys (Leh, Spiti and Bihar regions), C2- small standard ones including donkeys from Rajasthan and Gujarat while cluster C3 having donkeys from Baramati and Haryana region. Poitou cluster was phenotypically different from Cluster 1 as Eucledean cluster distance was maximum with donkeys of this cluster, followed by cluster 2 and cluster 3 . This information will be useful for breed classification of these local non-descript donkeys.
\end{abstract}

Keywords: Indian donkeys; Agro-climatic regions; Phenotypic clusters; Biometric indices

\section{Introduction}

In Equidae family, donkeys (Equus asinus), represents one of the oldest domesticated equine species [1,2]. Originally donkey has African wild ass, E. africanus asinus as its wild ancestor. Donkeys have been used for transportation of agricultural goods, building materials and people all over the world. In India, majority of the donkey population is owned by socially and economically deprived landless people and these animals serve as the source of livelihood for their masters and play an important role in their socio-economic status also. The contribution of donkeys has been enormous in agriculture, herding and carrying materials with migratory herds of cattle, sheep and goats, transportation of agricultural produce, house hold material and provision as well as material for building construction. Although donkeys support the rural livelihood and low income poor farmer's families by providing economy at minimal maintenance cost, they are not yet considered as farm animals. Donkeys are neglected and rarely studied. Due to their indiscriminate use without any proper feed and fodder, health status etc, these animals are also known as beast of burden [3]

As per $19^{\text {th }}$ livestock Census (2012), total equine population in India was about 1.14 million and donkeys constituted $28 \%$ of the total equines. Total donkey population in the country has decreased by $27.22 \%$ between $18^{\text {th }}$ and $19^{\text {th }}$ Livestock Census which is higher than the overall decrease $(9.6 \%)$ in equine population. This decrease in population might be due to their decreased working utility, as alternate economical sources of mechanization are available. Donkeys are scattered in almost every state in India and their statewise population is : Rajasthan $(0.81$ $\left.\mathrm{x} 10^{5}\right)$; Uttar Pradesh $\left(0.56 \times 10^{5}\right)$, Gujarat $\left(0.38 \times 10^{5}\right)$, Maharashtra $\left(0.29 \times 10^{5}\right)$, Bihar $\left(0.21 \times 10^{5}\right)$, Jammu \& Kashmir $\left(0.17 \times 10^{5}\right)$, Karnataka $\left(0.16 \times 10^{5}\right)$, Madhya Pradesh $\left(0.15 \times 10^{5}\right)$, Andhra Pradesh $\left(0.13 \times 10^{5}\right)$ and so on (1 $9^{\text {th }}$ Livestock Census 2012, Govt of India). In some geographic areas with restricted access, donkeys have adapted themselves to those particular agro-climatic conditions also. These donkeys are known as local non-descript small to medium sized donkeys. Some of the donkey populations available in different geographic areas in India have lot of differences in their physical appearances due to their adaptation and utilization in that particular area but these have not been classified into different breeds. In different parts of the world, donkey populations

*Corresponding author: Gupta AK, Pr. Scientist, National Research Centre on Equines, Sirsa Road, Hisar 125001, Haryana, India, Tel: +91 1662276748 276151; E-mail: akguptanrce@hotmail.coml

Received August 21, 2017; Accepted November 28, 2017; Published December 02, 2017

Citation: Gupta AK, Kumar S, Pal Y, Brahmane M, Kumar B, et al. (2017) Phenotypic Clustering of Indian Donkey Population Belonging to Six Agro-Climatic Regions. J Biodivers Endanger Species 5: 201. doi: 10.4172/2332-2543.1000201

Copyright: ( 2017 Gupta AK, et al. This is an open-access article distributed under the terms of the Creative Commons Attribution License, which permits unrestricted use, distribution, and reproduction in any medium, provided the original author and source are credited. 
have been described as separate breeds and beside their use in carting or pack animals, these have also utility as companion animal, donkey assisted therapy for human well-being and in leisure sports [3].

In order to phenotypically characterize the donkeys of India, we planned to analyze phenotypic diversity among donkeys in their natural habitat in different agro-climatic regions in India including Gujarat, Rajasthan, Maharashtra, Jammu \& Kashmir, Haryana, Bihar, Pune and Himachal Pradesh for their further categorization as distinct breed(s) by considering each population as a phenotypic cluster. This information should further serve for defining the breeds of donkeys in India.

\section{Methods and Materials}

\section{Animals and Agro-climatic regions}

In India, donkey population varies from place to place in its 15 different agro-climatic regions (www.agriinfo.in/?page=topic\&supe rid=1\&topicid $=425$; retrieved on 20.09 .16 at $12.50 \mathrm{PM}$ ). It was not easy to assess donkeys available in all these areas. On the basis of local donkey population, donkeys from six different agro-climatic regions (Figure 1) were selected for assessing their phenotypic and physical characteristics. The areas selected either presented a numerous donkey population or isolated population in different herds in that geographic location. Most of the donkeys included in this study were males (90\%) and adults ( $>3$ years of age). Except exotic French Poitou donkeys, all the local donkeys were meeting their nutritional requirement through grazing combined with stall feeding of concentrate mixture (200-400 g animal $^{-1}$ ) only during winter season.

Spiti (S) area in Himachal Pradesh: Zone 1 (Western Himalaya Region) Ninety seven donkeys from villages namely Lari, Mud, Kaza, Kiber, Tabo, Shichling as well as on the way to Pin valley (Guling, Tangati-1, Tangati-2, Mikkim, Sangnum, basin of Pin river) were selected to have an overall representation of donkey population in the Spiti valley. Spiti area has cold desertic conditions (a temperature $20^{\circ} \mathrm{C}$ to $-35^{\circ} \mathrm{C}$ with loam) with low vegetation cover.

Haryana (H): Zone 6 (Trans Gangatic Plains Region) Fifty two donkeys were selected from different villages in Hisar, Jind, Rohtak, Bhiwani, Sirsa and Kaithal districts. This region is semi-arid with temperature variation from 0 to $48^{\circ} \mathrm{C}$ with high vegetation cover.

Leh $(\mathrm{L})$ in Jammu \& Kashmir: Zone 1 (Western Himalaya Region) Fifty donkeys available in Leh town (donkey sanctuary, and with local inhabitants) as well as nearby areas upto Khardungla pass were selected for this study. Leh has also cold desert conditions. (Temperature varied

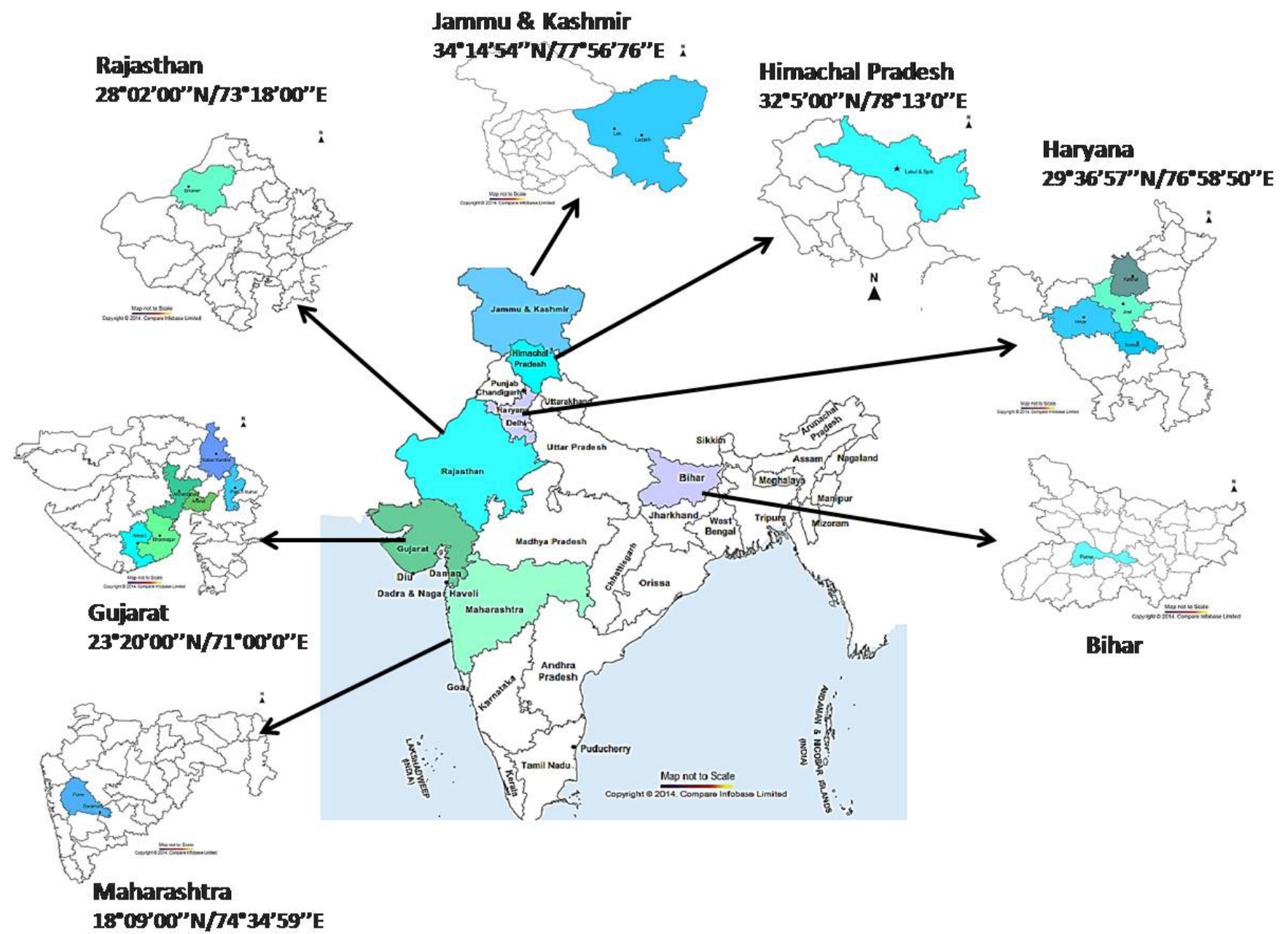

Figure 1: Depiction of different agro-climatic zones for selecting donkeys in India. 
between $30^{\circ} \mathrm{C}$ to $-40^{\circ} \mathrm{C}$ during summer and winter) and soil is loamy mixed with stones and gravels. The vegetation in this zone is very sparse.

Gujarat (G): Zone 13 (Gujarat Plains \& Hills Region) Gujarat has quite good quantity of donkey population (38834 donkeys as per Livestock Census 2012). Both white and grey coloured donkeys are available in different districts of Gujarat but only white donkeys both large and small ones were selected for their phenotypic characterization. Biometric indices were recorded for 56 selected animals during Vautha Animal Fair (Vautha, Amreli etc) as well as from other nearby areas in Gujarat. Gujarat has hot and humid climate (temperature $12^{\circ} \mathrm{C}$ to $41^{\circ} \mathrm{C}$, alluvial soils).

Rajasthan (R): Zone 14 (Western Dry region) Like Gujarat, Rajasthan has also good donkey population in different districts. A total of 81468 donkeys are available in different districts of Rajasthan. Seventy four donkeys were selected from Churu, Rajgarh, Ratangarh, Sardarsahar, Bikaner, Sikar, Jodhpur, Jhalawar, Baran, Kota as well as those assembled during health camps and equine fairs from different other areas for this study. Rajasthan has hot desert climatic condition (temperature $5^{\circ} \mathrm{C}$ to $45^{\circ} \mathrm{C}$, sandy soil) with little vegetation available during lean periods.

Baramati (Br), Pune: Zone 9 (Western plateau \& Hills region) About 29135 donkeys are available in different districts in Maharashtra. Donkeys (59) were selected from villages namely Panas, Kirloskarwadi, Maynee, Vita, Parawadi, Dound and Rahata around Baramati (Pune, Maharashtra). White, light and dark grey donkeys were available in the areas studied. These donkeys were being used for day to day activities of transport as pack animal. Also these were utilized in grape fields for applying farm yard manure. In Baramati, Pune the climate is mild with temperature variation from $8^{\circ} \mathrm{C}$ to $40^{\circ} \mathrm{C}$. Area is quite fertile and vegetation is good.

Bihar (Bh): Zone 4 (Middle Gangetic Plain Region) Seventy seven donkeys maintained by various small and marginal farmers in and around Patna, Buxar, Balia, Sonepur, Gaya, Jahanabad, Gaya, Rajgir, Nalanda, Bhojpur were included in this study. It is a fertile alluvial plain drained by the Ganga and its tributaries. The average temperature in July varies from $26^{\circ} \mathrm{C}$ to $41^{\circ} \mathrm{C}$ and that of January $9^{\circ} \mathrm{C}$ to $24^{\circ} \mathrm{C}$, average annual rainfall is between $100 \mathrm{~cm}$ and $200 \mathrm{~cm}$. The region had very good vegetation cover.

Poitou (P) donkey: Twenty nine exotic French Poitou donkeys maintained at an organized farm in Bikaner, Rajasthan were included in this study for comparative analysis of local donkey population. Being a part of Rajasthan, Bikaner has hot desert climatic condition (temperature $5^{\circ} \mathrm{C}$ to $45^{\circ} \mathrm{C}$, sandy soil). French Poitou (exotic) donkeys are maintained for the last twenty years at an organized farm, RajasthanZone 14 (Western Dry region). These donkeys are provided with $2 \mathrm{~kg}$ grain (Oat, gram, wheat bran and mineral mixture), $7 \mathrm{~kg}$ dry fodder and $21 \mathrm{~kg}$ green fodder.

\section{Biometric indices and physical characteristics}

Fifteen different biometric indices for phenotypic characterization of each donkey including height at wither (HW), body length (BL), heart girth (HG), face length (FL) and width (FW), ear length (EL) and width (EW), hoof length (HoL) and width (HoW), fore (FLL) and hind (HLL) leg lengths, height at knee (HK) and hock (HH), canon and gap between ears (pole) were recorded. Adult and apparently healthy donkeys of both the sexes were included in this study. Coat colour and other physical characteristic of individual donkeys including face appearance, body structure etc were also recorded along with good quality photographs for their documentation (Figure $2 \& 3$ )

\section{Statistical Analysis}

The biometric data was statistically analyzed using SPSS Package (7.1 version), while colour and other physical features were expressed in percentage/frequency. Phenotypic clustering analysis along with distance among clusters for individual parameters and overall cluster distance was done using Indostat software (8.1).

\section{Results}

Among the regions selected in this study, donkey population is on the verge of extinction in Leh (Jammu \& Kashmir) as their number has drastically decreased and is less than a few hundred. In other regions, donkey population varied from area to area within the same zone. Since these animals are widely scattered at different locations, therefore random sampling was done from different places. In total, biometric indices of seven local donkey populations along with Poitou breed of exotic donkey (French) were recorded.

\section{Physical characteristics including coat colour}

Physical appearance of each representative of various donkey populations from different agro climatic regions of India has been depicted in Figure 2 \& 3. In general, small to medium size donkeys were prevalent throughout different agro-climatic regions included in this study. Poitou donkey which is already an established breed had medium to large donkeys. Body of all the local donkeys from various agro-climatic zones was well developed with fairly strong bones. Their legs were thin and covered with small coarse hair. Donkeys observed in cold desert regions (Spit and Leh) were able to move and climb quickly on the steep and sloppy hills with pack load of 40-60 Kg. Most of the donkeys except white donkeys from Gujarat had a dorsal dark colour stripe along their back and shoulders and Zebra marking on legs. Mane or tail of all the donkeys was stiff and coarse. The tail was small and thin with a tasseled end except donkeys from Spiti and Leh areas, where comparatively long tail up to hock was observed. They had very dominant eyebrow ridges while lips were loose as compared to indigenous local horses. The body was sturdy displaying an alert attitude. Face was convex with black eyes and erect long ears. Neck was short while back was straight on top with sloppy sides. Donkeys were well adapted to their agro-climatic environment and ecology as they were totally dependent upon the grasses and roughages available within their reach for meeting their nutritional requirements. Working donkeys were docile in temperament and were tuned to carry 24-30 bricks (60 to $75 \mathrm{~kg}$ ) on their back in the plains and to pull $400-600 \mathrm{~kg}$ of load in cart.

Coat colour varied in different regions. In Rajasthan area, $70 \%$ of donkeys of Rajasthan were of grey colour and remaining animals were of white colour. Skin colour of all the donkeys was grey. In Spiti, coat colour of most of the animals was dark brown (44\%) with and without dark strip on back (22 and $20 \%$, respectively), grey (33\%) and black (25\%). In Gujarat, both white and grey coloured donkey were available in its different districts but only white large donkeys along with small ones were selected for phenotypic characterization of these donkeys. In Baramati area also, most of the donkeys were white (57.63\%), followed by grey (39\%), both light and dark with and without dark strip on back and brown $(3.33 \%)$. In another cold desert (Leh), donkeys were dark coloured, mainly dark grey (42\%), brown $(42 \%)$ and black $(16 \%)$ in colour. Coat was quite thick in all these donkeys which helped them in sustaining in very cold temperature also. In Haryana, most (90\%) 


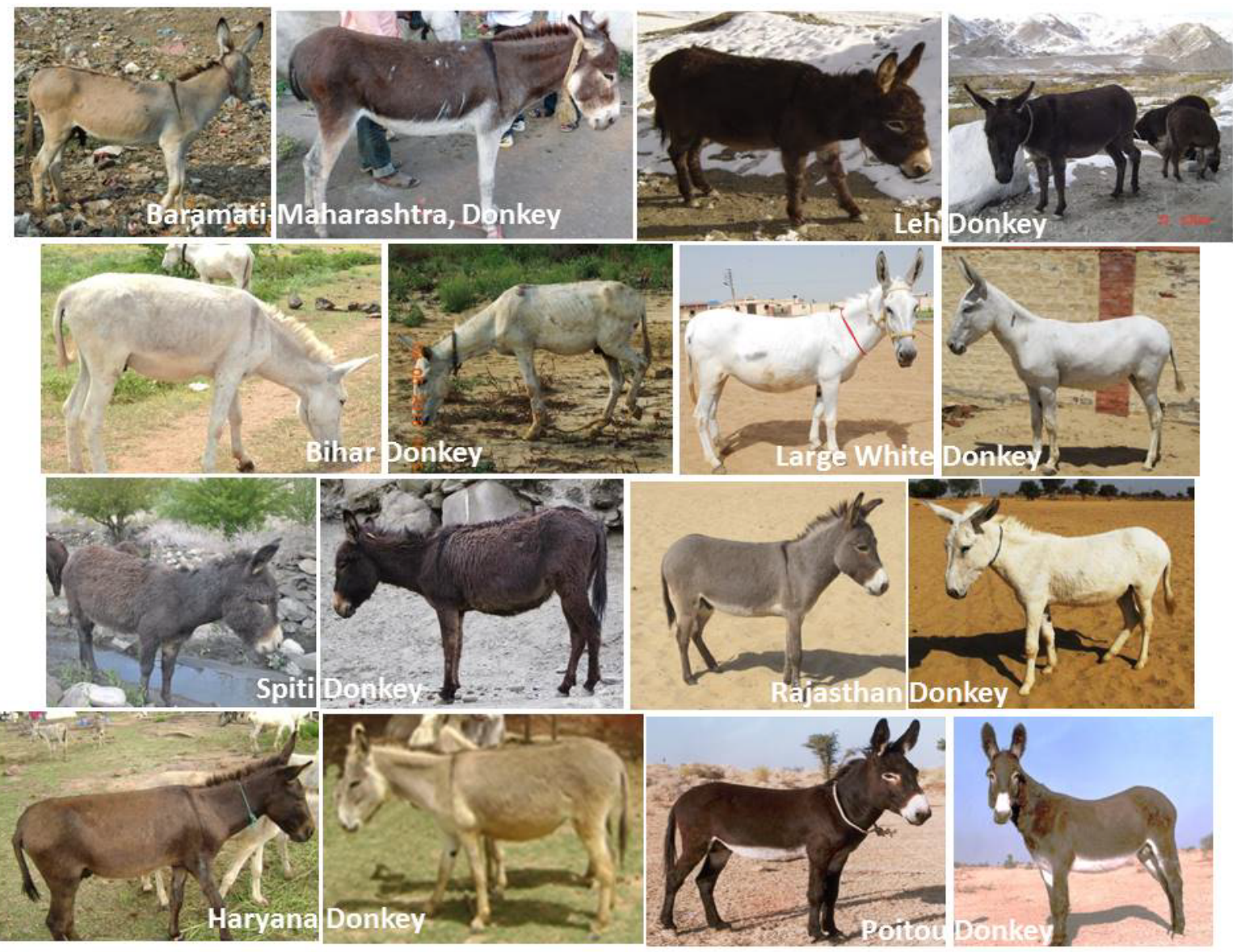

Figure 2: Representative animals of different donkey population showing their Physical features.

of the donkeys were grey coat coloured while in Bihar, grey coat colour $(54.17 \%)$ was prominent, followed by white grey $(36.11 \%)$ and brown (5.56\%). A few donkeys were having red sand colour (like wild ass). Coat colour of Poitou donkeys was bay black. Hair of donkeys belonging to Leh and Spiti areas were long (4-7 inches), thick, shining and coarse which help them in maintaining the body heat in cold desert conditions.

\section{Biometric indices}

The average body length of donkeys from Spiti, Gujarat, Rajasthan, Baramati, Bihar, Leh and Haryana areas was 97.09, 101.18, 97.60, $103.68,96.31,95.76$ and $109.22 \mathrm{~cm}$, respectively while Poitou donkeys had $138.79 \mathrm{~cm}$ length which was significantly higher than all the seven indigenous donkey population (Figure 4). Body length varied significantly $(\mathrm{P}<0.05)$ among the donkeys of different areas. Donkey population at Leh, Spiti and Bihar had significantly smaller body length as compared to donkey populations from Gujarat, Haryana and Baramati. Similarly, the height at withers of donkeys in all the three areas was significantly lower than that in Poitou and other indigenous populations. Further, donkeys at Leh had the smallest height at withers $(88.61 \mathrm{~cm}$ or 34.89 inches) followed by Spiti donkeys $(91.89 \mathrm{~cm}$ or 36.18 inches) and Bihar donkeys (93.68 $\mathrm{cm}$ or 36.88 inches). The height at withers varied significantly $(\mathrm{P}<0.05)$ among donkeys of different locations. Among various local donkey populations, donkeys from Haryana had significantly $(\mathrm{P}<0.01)$ higher height at withers than rest of the populations. The Poitou donkey's length and height are found to be significantly higher as compared to all indigenous donkeys. The heart girth also varied significantly $(\mathrm{P}<0.05)$ among the donkeys of different locations. Donkeys from Leh had significantly lower $(98.34 \mathrm{~cm})$ body girth than other populations.

Physical appearance of face was also evaluated in terms of FL, FW, EL and EW in all the indigenous donkey populations along with established Poitou breed (Figure 4). Poitou donkeys had maximum values for all these indices which were also significantly higher than local indigenous populations. Face length of donkeys from Spiti, Gujarat and Baramati were at par with each other while donkeys from Leh had smallest face length. Face width of donkeys from Spiti $(14.32 \mathrm{~cm})$, Gujarat $(14.23 \mathrm{~cm})$ and Rajasthan $(14.80 \mathrm{~cm})$ was at par with each other and their values indicated lean/narrow face of these populations. Among Indigenous donkeys, donkey from Baramati area had significantly wider face as compared to other ones. Mean ear length $(19.95 \mathrm{~cm})$ and ear width $(12.97 \mathrm{~cm})$ were smallest one in Spiti and Leh donkeys, respectively. Ear length and width of Gujarat, Rajasthan and Baramati donkeys were almost at par with each other. Gap between ear bases (pole) was maximum and significantly higher in Baramati donkeys than Poitou, Gujarati and Rajasthan donkeys. However, the values were at par with Spiti and Leh donkey populations. The variations among the donkeys of different locations with respect to FL, FW, EL, EW and pole were significant. 

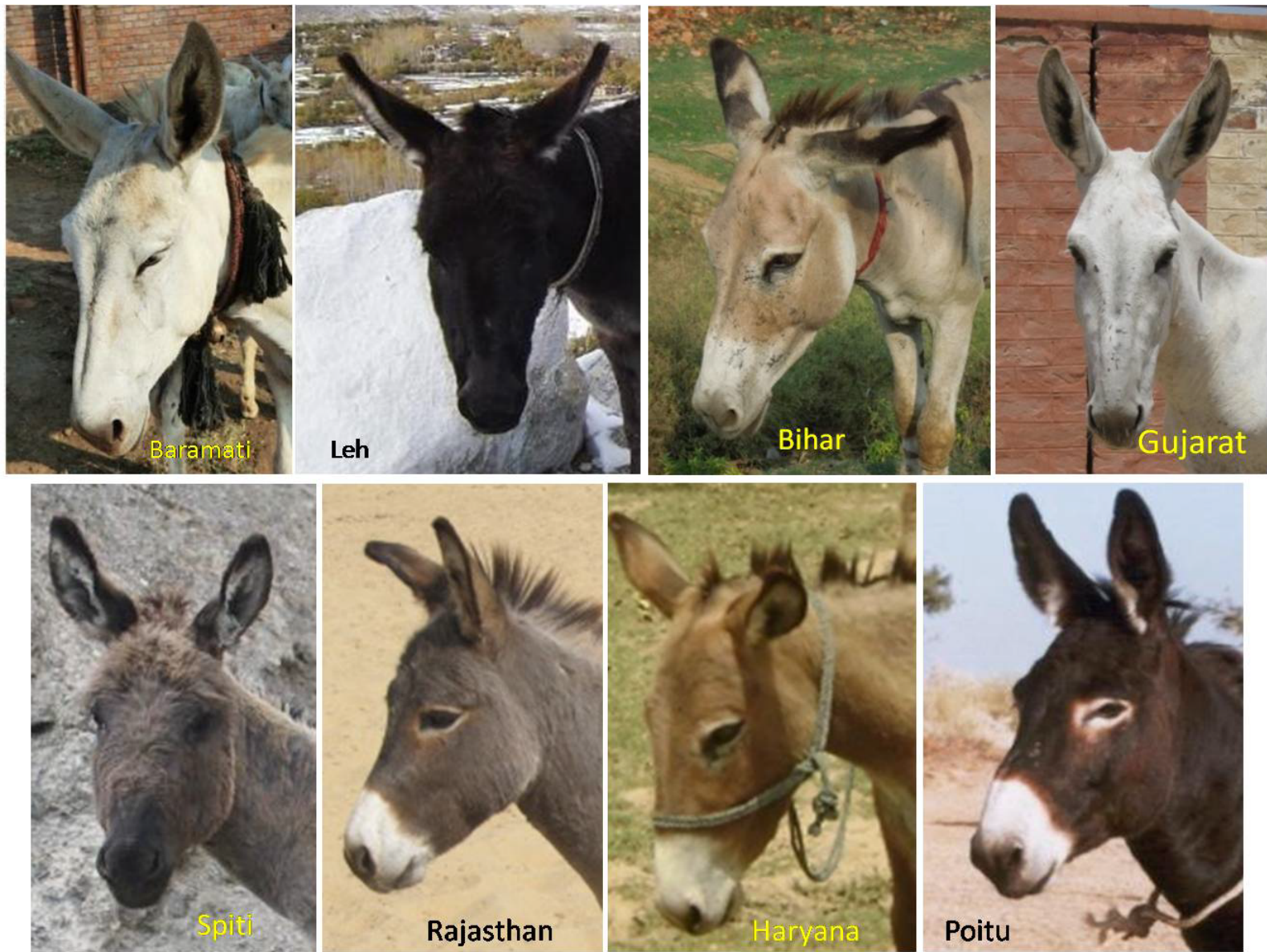

Figure 3: Faces of donkey population from different agro-climatic zones showing typical characteristics.

Leg length (fore and hind) which contribute towards height of the donkeys were also studied. FLL, HK, canon, HLL and height at hock $(\mathrm{HH})$ were significantly higher in Poitou donkeys than all Indigenous donkey populations. Among seven local populations, FLL, HK and HLL in Spiti and Canon and HH in Leh population were significantly lower than other local population. Further, FLL was significantly different in almost all the local Indian populations. However, HLL, HH and canon were almost same in donkeys from Gujarat, Rajasthan and Baramati areas. FLL, HK, canon, HLL and $\mathrm{HH}$ were significantly different among the donkeys of different locations. Average hoof length $(11.60$ $\mathrm{cm})$ and width $(8.72 \mathrm{~cm})$ were maximum and significantly higher in Poitou donkeys than all indigenous donkey populations. Among local populations, hoof length $(6.24 \mathrm{~cm})$ and width $(5.33 \mathrm{~cm})$ were the smallest in Rajasthan and Leh populations, respectively. Their values in other local populations were at par with each other. Hoof length and width were significantly different among the donkeys of different locations.

Cluster analysis of different donkey populations (Figure 5) revealed that French Poitou donkeys formed a totally different cluster (C4) as compared to all the seven Indian donkey populations. Indian donkey populations were divided in three clusters. First cluster (C1) having miniature donkeys from Spiti, Leh and Bihar which was closely linked with second (C2) cluster has donkeys from Gujarat and Rajasthan region while third (C3) cluster included donkey population from Baramati and Haryana regions. Among these four clusters, phenotypically maximum distance was observed between clusters $\mathrm{C} 4$ vs. $\mathrm{C} 1$, followed by $\mathrm{C} 4$ vs. C2 and $\mathrm{C} 4$ vs. $\mathrm{C} 3$ (Table 1). Further within individual clusters, maximum phenotypic distance was observed in cluster 3 (2.492) followed by cluster 1 (1.896 and cluster 2 (1.1.82) due to clubbing together of two to three populations from different regions.

\section{Discussion}

Though donkey, which was earlier considered as the tractor of the common man, is now not a highly valued animal in different parts of the world. Donkeys' functional potential is growing and standardized breeds sell for relevant amounts of money, which though do not reach the importance of horse, are building their path. About 185 breeds are defined and these are still in use as hobby keeping of single animals despite of their use in mule production, breeding, trekking, riding, herd protection and use of their milk in cheese and cosmetic industry as well as use of their meat in sausage making (SAVE foundation project report 2013, http://www.agrobiodiversity.net/topic network/donkey/ Donkey/Donkey-ReportEN.pdf retrieved on 20.06.2017). In India, though mechanization has over-powered animal power in transport, agriculture and other miscellaneous routine activities but equine power especially donkey power is still in use by its poor owners for earning their livelihood as well as in difficult hilly terrains where motorable vehicle cannot go. India has about 0.413 million donkeys which are known as "Beast of Burden" [3]. Indian donkeys, available in different agro-climatic areas, have never been characterized for their phenotypic 

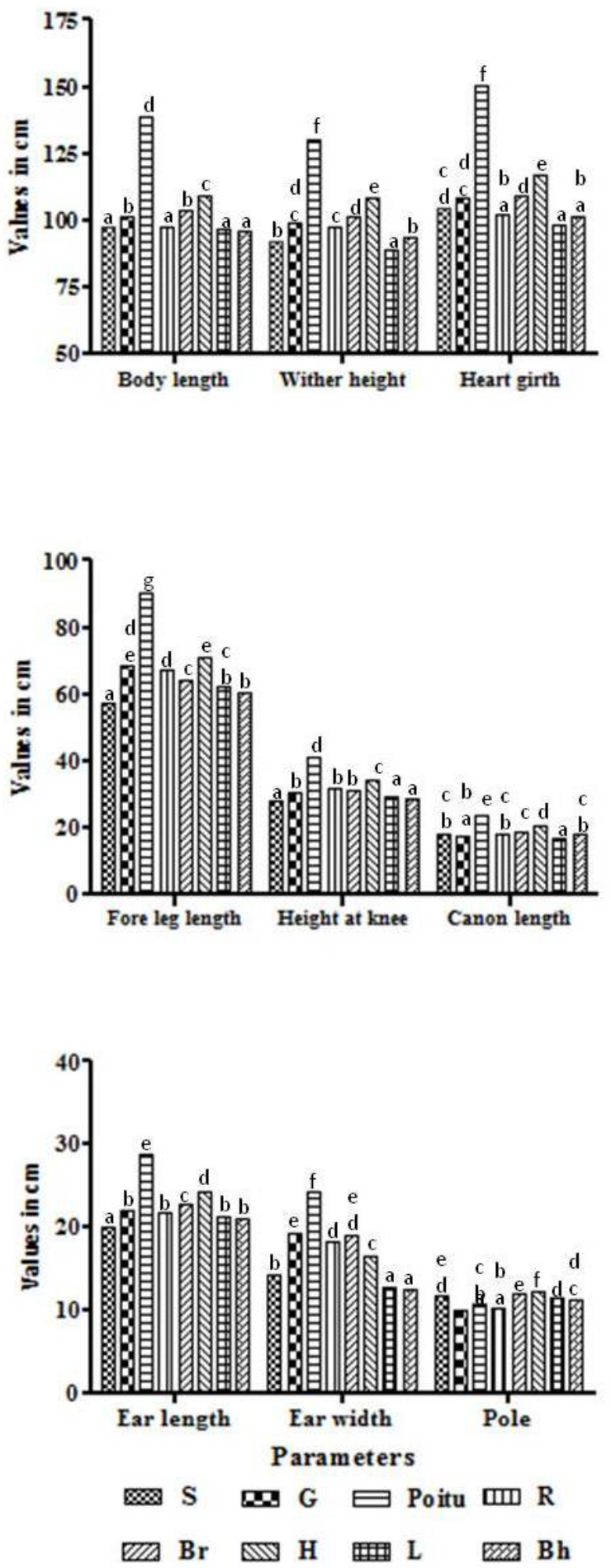
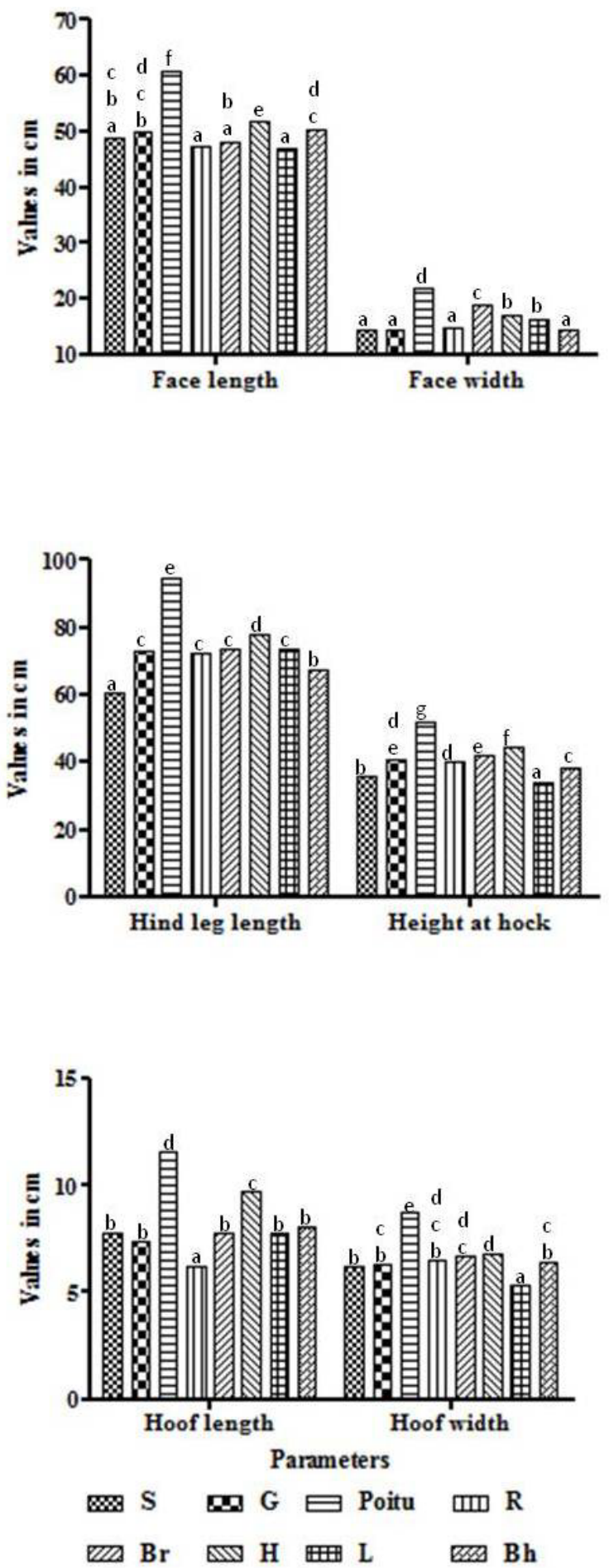

Figure 4: Biometric indices of donkey populations belonging to different agro-climatic areas including Spiti region was presented as (S), Gujarat (G), Poitou, Rajasthan $(\mathrm{R})$, Baramati $(\mathrm{Br})$, Haryana $(\mathrm{H})$, Leh $(\mathrm{L})$ and Bihar $(\mathrm{Bh})$, respectively. (Small alphabet above each column represents significant difference among each indices).

or genetic characteristics as well as identified as a separate breed like exotic donkeys namely Poitou, French donkeys; Italian breed (Amrat), American Mammoth, Burro, donkey of USA; Asinara donkey or Asinara ass of the Island of Asinara; Asin of Niger, Asno of Chile etc (http://
en.wikipedia.org/wiki/List_of_donkey_breeds retrieved on 20.09.2017, http://www.fao.org/3/a-a1250s/List breeds.pdf).

Considering Indian donkey's phenotypes and phaneroptics, donkeys from Leh were categorized as miniature donkeys (34.89 


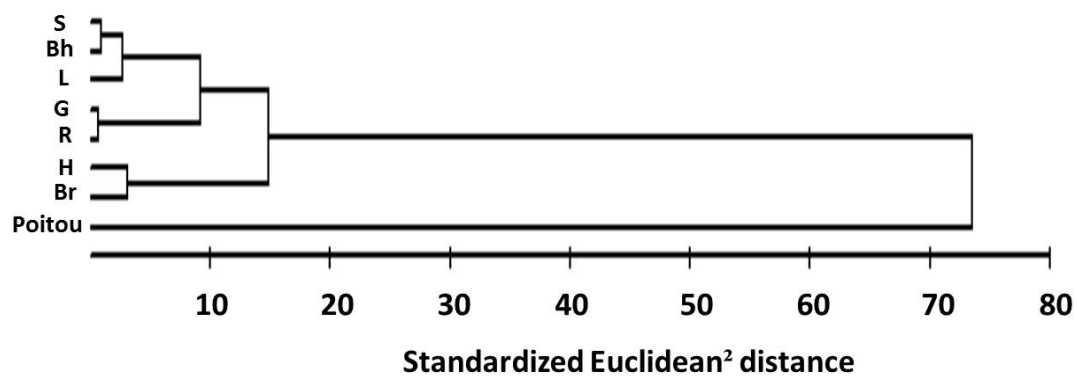

Figure 5: Cluster analysis presented through Ward's minimum variance dendrogram. Donkeys from Spiti region were represented by $S$, Gujarat=G, Poitou, Rajasthan=R, Baramati=Br, Haryana=H, $\mathrm{Leh}=\mathrm{L}$ and Bihar $=\mathrm{Bh}$

\begin{tabular}{|c|c|c|c|c|}
\hline Clusters & C1 & C 2 & C 3 & C 4 \\
\hline C 1 & $1.896^{*}$ & 3.038 & 3.885 & 10.558 \\
\hline C 2 & & $1.182^{*}$ & 3.740 & 9.227 \\
\hline C 3 & & & $2.492^{*}$ & 7.584 \\
\hline C 4 & & & & $0.000^{*}$ \\
\hline
\end{tabular}

"indicates distance within cluster.

Table 1: Eucledean Distances among and within clusters.

inches) and Poitou breed donkey as large donkey. Donkeys from Spiti (36.18") and Bihar (36.88") were close to miniature donkeys while rest of the local non-descript population were clustered as small standard donkeys. Physical appearance wise, donkeys from Leh and Spiti were black or brown in colour, small in size with thin and narrow body structure covered with a thick protective coat of hair. Further, based on similarity in their phenotypic characteristics namely, body length, body width, face length and width, ear length and width, these can be clubbed together as one cluster. Donkey from Leh had the smallest hoof width. Further, these donkeys had a very limited movement within cold and desert agro-climatic region; therefore chances of mixing and cross breeding with donkeys of other areas were also lower. Among the small donkeys or near miniature donkeys, donkey population from Bihar can also be clubbed with Leh and Spiti donkeys, as all these donkeys were phenotypically of similar body height and length except their hair which were small and not required in Bihar donkey due to hot climatic conditions. As per data of this study, these donkeys from Leh, Spiti and Bihar were grouped as a separate phenotypic cluster which was significantly distinct from Poitou and other indigenous donkey populations.

On the basis of biometric indices and physical appearance, donkeys from Gujarat and Baramati regions seems to be similar in their structure except percent variations in coat colour. Most of the donkeys were grey in colour (white, light or dark grey). Their body length, height at wither, heart girth, hind leg length, height at hock, face length were at par with each other which leads to club them together as a separate phenotypic cluster. Though these donkeys fall in two different agro-climatic regions but free movement of these donkeys from one region to other region during their sale and purchase in equine fairs as well as shifting of donkey owners between these regions for earning livelihood may be the main reason for their phenotypic similarity. During our visit to Vautha fair in Gujarat, it was observed that most of buyers of donkeys were from Maharashtra state. It confirms that these donkeys must have been from Gujarat. Further, indiscriminate breeding is also prevalent among these donkeys as donkey owner do not care for donkey breeding.

Donkeys from Rajasthan regions were significantly $(\mathrm{P}<0.05)$ smaller than donkeys of Gujarat and Baramati regions in terms of their body length, height at wither, body girth, face length, ear length, ear width but rest of the biometric indices were at par with donkeys of both the above regions. Thus these cannot be clubbed as a separate phenotypic cluster. Donkeys from Haryana (Zone 6-Trans Gangatic Plains Region) were significantly $(\mathrm{P}<0.05)$ larger in almost all the indices except their ear width from rest of the indigenous donkey populations. On the basis of these characteristic, phenotypically these can be defined as a separate cluster.

Comparing the donkeys of Indian origin with those of exotic donkeys, the body length of Hassawi donkeys (178.8-185.8 cm) of Egypt and Iraq [4], Poitevin, Catalan donkeys $(143 \mathrm{~cm})$ of Morocco \& France, [5]; Balkin donkeys $(110.3-117.2 \mathrm{~cm})$ of Siberia, [6] was exceptionally high than all indigenous donkey populations of India. Height at withers which is reflection of overall body constitution of an individual was also observed to be high in Hassawi donkeys of Egypt \& Iraq, Poitevin \& Catalan donkeys and Bulgarian donkeys [7] as these donkeys come under the large donkey category. Most of the Indian donkeys match with Balkin, Turkish \& Cameroon donkeys with respect to their height at withers $[6,8,9]$. In this study, we included most of the male donkeys of age group $>3$ years. A few female donkeys were included in this study but it should not affect the parameters since sexual dimorphism is not expressive in donkeys [10] like horses [11] and other mammalian species like rabbits and guinea pigs.

In general, on the basis of physical appearance and biometric indices, this study revealed that in terms of miniature, small standard, large standard and Mammoth donkeys, Indigenous donkey can be phenotypically clustered in two groups namely miniature donkeys (Leh, Spiti and Bihar regions) and small standard donkey comprising donkey from Gujarat, Baramati, Rajasthan and Haryana while exotic Poitou donkeys is an out-group. However, cluster analysis revealed that miniature donkeys namely donkeys from Spiti, Leh and Bihar formed cluster $1(\mathrm{C} 1)$, while small standard donkey populations were further divided in two clusters based on their body length, heart girth, leg lengths, face length and width: $\mathrm{C} 2$ comprising donkeys from Rajasthan and Gujarat region while Clustrer C3 having donkeys from Haryana and Baramati region. Coat colour cannot be considered as one of the criteria for differentiation and clustering except in cold desert areas of India agro-climatic regions where most of the donkeys were black or brown in colour while donkeys in rest of the climatic regions were 
Citation: Gupta AK, Kumar S, Pal Y, Brahmane M, Kumar B, et al. (2017) Phenotypic Clustering of Indian Donkey Population Belonging to Six AgroClimatic Regions. J Biodivers Endanger Species 5: 201. doi: 10.4172/2332-2543.1000201

grey in colour. In view of the above, it is imperative to do genotypic characterization also for final clustering and characterizing as a breed.

\section{Acknowledgement}

Authors are thankful to Directors and Veterinary Officers of State Animal Husbandry Departments of Himachal Pradesh, Jammu and Kashmir, Maharashtra, Gujarat, Rajasthan and Haryana for their kind support in carrying out this study. Thanks are also due to Director, NRCE for extending all facilities in carrying out this work.

\section{References}

1. Hemming $F$ (2003) Opinion 2027 (Case 3010). Usage Of 17 Specific Names Based On Wild Species Which Are Pre-Dated By Or Contemporary With Those Based On Domestic Animals (Lepidoptera, Osteichthyes, Mammalia): Conserved. Bull Zool Nomenclat 60: 81-84.

2. Grubb P (2005) Order Perissodactyla. In Wilson, D.E.; Reeder, D.M. Mammal Species Of The World: A Taxonomic And Geographic Reference (3rd edition), Oclc 62265494.

3. Varshney JP, Gupta AK (1994) The donkey and it potential - a review. Int J Anim Sci 9: 157-167.

4. Shawaf T, Almathen F, Al-Ahmad J, Elmoslemany A (2016) Morphological characteristics of Hassawi Donkey, Eastern Province, Saudi Arabia. Alexandria $J$ Vet Sci 49: 178-183.

5. Boujenane I, Machmoum M (2008) Body measurements of donkeys of Poitevin and Catalan breeds and their crossbreds in Morocco. Revue d'elevage et de medicine veterinaire des pays tropicaux 61: 63-67.

6. Ljubodrag S, Vladimir D, Predrag S, Nada L, Ivica R, et al. (2015) Morphological, biochemical and hematological characterization of endangered Balkan donkey breed. Acta Veterinaria-Beogard 65: 125-136.

7. Vlaeva R, Georgieva S, Barzev G, Ivanova I (2016) Morphological and phenotypic characteristics of donkeys in some regions of Bulgaria. Trakia $\mathrm{J}$ Sci 1: 92-95.

8. Yilmaz O, Ertugrul M (2012) The morphologic traits of donkeys raised in east and southeast of Turkey. Hayvansal Uretim 53: 10-13.

9. Ebani AL, Vall E (2005) Dry season effect on live weight and some body dimensions of working donkeys in the Sudano-sahel region of Cameroon. Tropicultura 23: 48-53.

10. Kefena E, Beja-Pereira A, Han JL, Haile A, Mohammed YK, et al. (2011) Ecogeographical structuring and morphological diversities in Ethiopian donkey populations. Livest Sci 141: 232-241.

11. Koch W (1954) Lehrbuch der allgemeinen Tierzucht. Stuttgrat: Ferdinand Enke Ferlag, Germany. 